\title{
Significance of Location Based Service Applications in Smartphones Using GPS and Web Service
}

\author{
Akinyele Okedola Akinleye ${ }^{1}$, Sarumi Akingbola Jamiu ${ }^{1}$, Green Olawole Olakunle ${ }^{1}$, \\ Badmus Abdulsamad ${ }^{2}$ \\ ${ }^{1}$ Department of Computer Engineering, Lagos State Polytechnic, Lagos, Nigeria \\ ${ }^{2}$ Department of Electrical/Electronic Engineering, University of Lagos, Lagos, Nigeria \\ Email address: \\ leye_akinyele@yahoo.com (A. O. Akinleye), sarrosoft@gmail.com (S. A. Jamiu), greenoo.@mocped.edu.ng (G. O. Olakunle), \\ toyin_ng@yahoo.com (B. Abdulsamad)
}

\section{To cite this article:}

Akinyele Okedola Akinleye, Sarumi Akingbola Jamiu, Green Olawole Olakunle, Badmus Abdulsamad. Significance of Location Based Service Applications in Smartphones Using GPS and Web Service. International Journal of Intelligent Information Systems.

Vol. 8, No. 6, 2019, pp. 97-101. doi: 10.11648/j.ijiis.20190806.11

Received: December 7, 2018; Accepted: April 29, 2019; Published: January 4, 2020

\begin{abstract}
Earlier smartphones came with fewer functions but Location Based Service (LBS) were confined to simple GPS tracking device. But today, advance wireless communication system provided current smartphones with GPS service and cheaper data service fees. Apparently, LBS applications are emerging technology solutions for most businesses to connect millions of customers within close proximity. However, many e-commerce websites today are still operating without locationbased service to easily connect buyers and sellers in the same locality. Nevertheless, the growth of LBS technology and LBS market have raised privacy concerns due to potential abuse of location information. This study aims to highlight the significance of location-based service and how it helped tech companies to drive significant revenue growth. It equally validates the research model focusing on privacy concern as moderator of post adoptive behavior associated with locationbased applications. We used risky shift phenomenon research method to conduct an online survey using Google docs on 500 businesses. The study tends to test the effects of major variables Unified Theory of Acceptance and Use of Technology (UTAUT) on LBS usage intention and actual use. We also test the hypothesis on post adoptive behaviorusing risky shift phenomenon research on over66 users of LBS application. The research findings support the hypothesis of moderating effect of privacy concern on performance expectancy and continuous usage is strong.
\end{abstract}

Keywords: Location-Based Applications, E-Commerce, Risky Shift Phenomenon, Post Adoptive Behavior

\section{Introduction}

The major significance of smartphones is to deliver valuable services. Location-Based Service(LBS) is a set of applications that exploit the knowledge of the geographical position of a client mobile device in order to provide services based on that information. They are also open to new areas for developers, cellular providers to develop and provide value-added services like advising clients of current traffic conditions, providing routing information, helping the users to find nearby shopping malls, taxi ATM machine. Smartphones have completely changed LBS with their powerful operating systems and various applications. LBS applications with a wide variety of business models have emerged, and LBS and social networking service (SNS) have been combined. Furthermore, location-based advertisements have appeared, enabling location-based commerce(Lcommerce), an enhanced version of mobile commerce. These days, most online/mobile information services, such as portals, maps, SNS, Google search engine and online yellow pages, provide requested information based on the users' location information. According to recent report by berg Insight [1], mobile location-based service (LBS) is gradually achieving mainstream market acceptance. At the end of 2013, smartphone adoption had reached 67 percent in North America and 58 percent in the European Union. Berg Insight estimates that about 50 percent of all mobile subscribers in Europe were frequent users of at least one location-based service at the end of 2013. 
In North America where adoption of GPS-enabled handsets is still somewhat higher, an estimated 60 percent of all handset users now access location-based services regularly. The LBS increase in usage and the total number of active users has finally translated to a significant revenue growth, especially for leading companies like Google and Facebook. In 2013, total LBS service revenues in the European Union reached an estimated $€ 735$ million and Berg Insight forecasts LBS revenues in the region to grow to $€ 2.3$ billion by 2018. In North America, revenues are forecasted to grow from almost US\$1.8 billion in 2013 to nearly US\$ 3.8 billion by 2018 .

There are many alternative ways to categorize LBS. LBS are divided into eight service categories based on primary function: mapping and navigation, local search and information, social networking and entertainment, recreation and fitness, family and people locator services, mobile resource management, mobile advertising, as well as other enterprise and B2B services.

Developing countries are caught up in the worldwide mobile technology evolution and Africa is no exception, though a bit slower. Up until the year 2000, 50 of the 54 African countries had no mobile phone coverage; only South Africa, Egypt, Morocco and Senegal had mobile phone coverage [2].

In Africa, especially in rural areas, the mobile network infrastructure is made up of mainly second wireless network generation $(2 \mathrm{G})$ networks and South Africa having the most advanced mobile network in Africa is a good indication of this. VODACOM South Africa with the largest network coverage in the country has about 99.7 percent $2 \mathrm{G}$ coverage and 54 percent $3 \mathrm{G}$ coverage. Even with the limitations presented by the mobile infrastructure, many other services can be introduced to the African populace to optimize the major communication technological penetration available to them: the mobile technology. Such new services include mobile money services; location-based content services, menu driven information services, etc.

A location-based service (LBS) is a software level service that uses location data to control features. As such LBS is an information service and has a lot of uses in social networking today as information, in entertainment or security, which is accessible with mobile devices.

LBS has variety of context it can be used, such as health, indoor object search, entertainment, work, personal life, transportation, e-commerce, etc.

LBS is critical to many businesses as well as government organizations to drive real insight from data tied to a specific location where activities take place. The spatial patterns that location-related data and services is one of its most powerful and useful aspect where location is a common denominator in all these activities and can be leveraged to better understand relationships and patterns.

LBS include services to identify a location of a person or object, such as discovering the nearest banking cash machine (ATM) or whereabout of a $\mathrm{m}$ friend or employee. LBS include parcel tracking and vehicle tracking services. LBS can also include mobile electronics commerce when taking the form of coupons or advertising directed at customers based on their current location. They include personalized weather services on mobile phones and even location-based games.

\section{Methodology}

This study aims to test the research model shown in figure 1 below based on the perceptions of actual users of LBS smartphone applications in order to understand their post adoptive behaviours according to their level of privacy concerns. The research model was designed to verify the impact of the major variables of UTAUT-performance expectancy, effort expectancy and social influence on the continuous usage intention of LBS. A causal relationship between continuous usage and actual use as measured by a surrogate variable, usage frequency, is also assessed. Finally, privacy concerns, which are very important in the LBS context, are included in the research model as a moderating variable. Here, all of the paths in the suggested research model are tested with overall sample first, and the samples are them divided into two groups according to their level of privacy concerns to determine the structural differences between the sub-models.

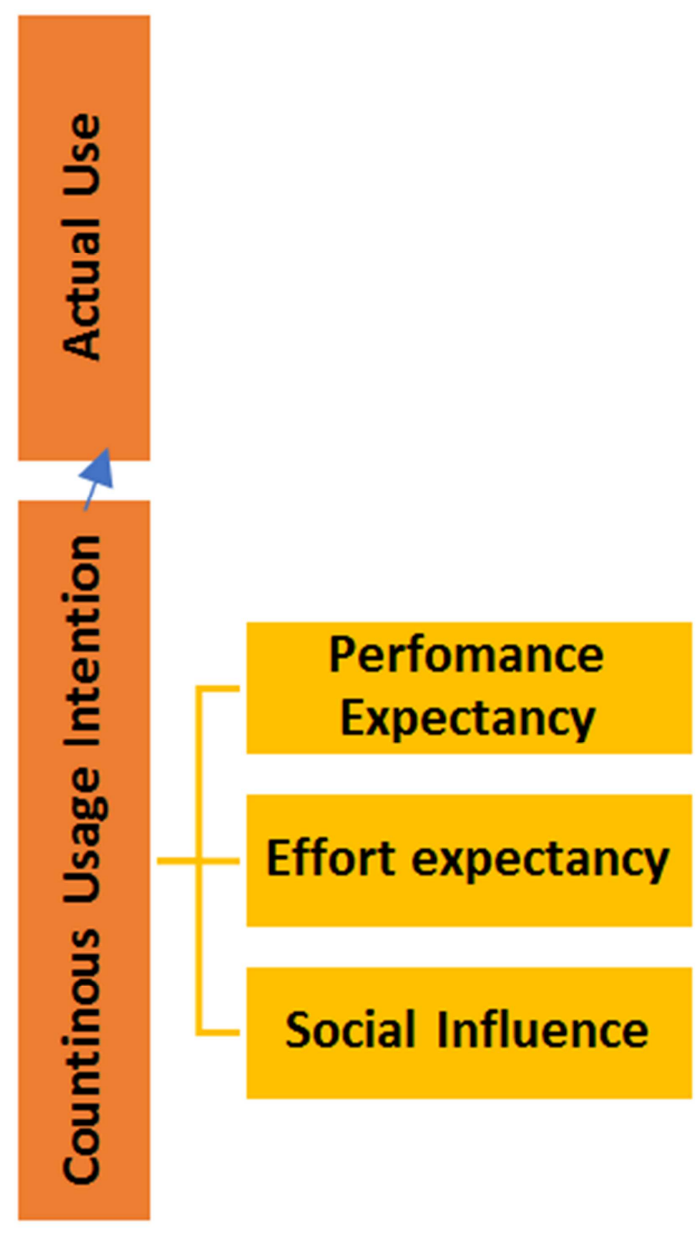

Figure 1. Research Model. 


\subsection{Research Construct Operational Definition}

Table 1. Research Terminology Definitions.

\begin{tabular}{ll}
\hline Construct & Operational definition \\
\hline Performance expectancy (PE) & The degree to which people believe that they are using LBS can help them accomplish their goals \\
Effort Expectancy (EE) & The degree of users' perceived ease of LBS use \\
Social Influence (SI) & The degree to which people that are important to them think they use LBS \\
Continuous Usage Intension (CUI) & The degree to which LBS are planned to be used continuously in the future \\
Actual Use (AU) & $\begin{array}{l}\text { The degree to which LBS is actually used } \\
\text { The degree to which an individual is concern about the collection, improper access, errors, and secondary use of } \\
\text { Privacy Concern (PC) }\end{array}$ \\
\hline
\end{tabular}

Table 2. Survey Items Definitions.

\begin{tabular}{ll}
\hline Construct & Survey Items \\
\hline PE & PE1. I find that LBS are useful. \\
& PE2. Using LBS increases my living and working productivity. \\
& PE3. Using LBS improves my living and working efficiency. \\
PE4. LBS are useful for achieving my personal goals. \\
EE1. Learning to use LBS is easy for me. \\
EE2. Skillfully using LBS is easy for me. \\
EE3. I found it easy to learn to use LBS. \\
EE4. For me, using LBS is an easy task. \\
SI1. People who influence me think that I should use LBS. \\
SI2. People who are important to me think that I should use LBS. \\
SI3. People around me help me use LBS. \\
SI4. My family and friends support my use of LBS. \\
CUI1. I will be using LBS frequently. \\
CUI2. I will be using LBS regularly. \\
CUI3. I intend to use LBS continuously. \\
CUI4. I will continue to use LBS in the future. \\
AU1. How many times do you use LBS in a month? \\
[1: Less than one time, 2: More than 5 times, \\
3: More than 20 times, 4: As frequently as possible] \\
PC1. I am concerned that the company is collecting too much location information about me. \\
PC2. I am concerned that the company may not take measures to prevent unauthorized access to my location information. \\
PC3. I am concerned that the company may keep my location information in an inaccurate manner in their database. \\
PC4. I am concerned that the company may share my location information with other parties without obtaining my authorization. \\
PC5. Overall, I feel unsafe about providing location information to the company through the use of LBS.
\end{tabular}

The Table 1 above showed the operational definitions and survey items. All of variables except for actual use were measured using a 7-point Likert scale. In another recent study on the actual use of mobile web browsing services, correlation analyses among variables related to usage behavior were conducted, proving that usage frequency represents usage behavior very well [3]. Therefore, actual usage behavior is measured as the usage frequency of LBS in this study.

Performance expectancy is the degree to which one believes that the use of a certain technology will be useful for enhancing task performance. This is similar to the usefulness of Technology Acceptance Model. [4] If we can achieve an objective using location information about the nearest taxi, restaurant, subway station or hospital the performance expectancy of LBS will be fulfilled. i.e., the usefulness of LBS applications in providing ubiquitous and instant accessibility as well as accurate and valuable information will affect its continuous usage. We conclude that the anticipation of the benefits of using LBS will have an effect on continuous usage intention:

\subsection{Data Collection and Sample Characteristics}

This study aims to validate the research model shown in figure 1 based on the perception of actual users of LBS applications. An online survey based on Google docs was conducted. The URL link was sent via e-mail or by WhatsApp application to 100 Nigerian smartphone users, and replies were gained from 84 actual or experienced users of LBS applications installed on their smartphones; thus, respondents has already adopted LBSto determine whether the respondents were users of LBS applications, they were initially asked to note all the different types of smartphone applications they have downloaded. As a result, data from 66 people who did not check LBS applications as downloaded were excluded from the final analysis. The demographic characteristics of the sample are shown in Table 3 below

Location based android applications considered in this research were just Uber, Badoo and Jiji mobile applications 
Table 3. Demographic characteristics of the sample.

\begin{tabular}{llll}
\hline Attributes & & Frequency & \% \\
\hline \multirow{2}{*}{ Gender } & Male & 43 & $66 \%$ \\
& Female & 23 & $38 \%$ \\
Age & $20-29$ & 22 & $33 \%$ \\
& $30-39$ & 36 & $55 \%$ \\
Job & Over 40 & 8 & $12 \%$ \\
& Student & 56 & $85 \%$ \\
Main purpose of using LBS & Employed & 10 & $15 \%$ \\
& Information Search & 52 & $79 \%$ \\
& Location based social network & 12 & $18 \%$ \\
& others & 2 & $3 \%$ \\
\hline
\end{tabular}

\section{Data Analysis and Results}

Table 4. UTAUT Hypothesis Test Result.

\begin{tabular}{lllll}
\hline Path & Path Coefficient & t-value & p-value & Result \\
\hline HI & 0.41 & 4.93 & 0.000 & Supported \\
H2 & 03.0 & 3.90 & 0.000 & Supported \\
H3 & 0.65 & 1.00 & 0.319 & Rejected \\
H4 & 0.51 & 9.95 & 0.000 & Supported \\
\hline
\end{tabular}

$* \mathrm{HI}=$ Performance Expectancy - Continuous Usage Intention.

$* \mathrm{H} 2=$ Effort Expectancy - Continuous Usage Intention.

*H3 = Social Influence - Continuous Usage Intention.

*H4 = Continuous Usage Intention - Usage Frequency.

Table 5. Factor Loading and Cross Loading of the Latent Constructs.

\begin{tabular}{llllll}
\hline & PE & EE & SI & CUI & UF \\
\hline PE1 & 0.88 & 0.65 & 0.45 & 0.34 & 0.30 \\
PE2 & 0.95 & 0.43 & 0.65 & 0.55 & 0.29 \\
PE3 & 0.94 & 0.56 & 0.43 & 0.43 & 0.47 \\
PE4 & 0.96 & 0.41 & 0.31 & 0.54 & 0.51 \\
EE1 & 0.42 & 0.91 & 0.41 & 0.45 & 0.43 \\
EE2 & 0.71 & 0.89 & 0.32 & 0.43 & 0.41 \\
EE3 & 0.69 & 0.94 & 0.61 & 0.34 & 0.53 \\
EE4 & 0.51 & 0.88 & 0.71 & 0.33 & 0.48 \\
SI1 & 0.71 & 0.33 & 0.93 & 0.53 & 0.32 \\
SI2 & 0.42 & 0.43 & 0.94 & 0.21 & 0.24 \\
SI3 & 0.32 & 0.51 & 0.92 & 0.42 & 0.35 \\
SI4 & 0.51 & 0.66 & 0.91 & 0.67 & 0.46 \\
CUI1 & 0.44 & 0.32 & 0.41 & 0.97 & 0.37 \\
CUI2 & 0.56 & 0.72 & 0.23 & 0.99 & 0.51 \\
CUI3 & 0.72 & 0.21 & 0.41 & 0.91 & 0.32 \\
CUI4 & 0.43 & 0.11 & 0.42 & 0.96 & 0.35 \\
UF & 0.43 & 0.32 & 0.51 & 0.67 & 1.0 \\
\hline
\end{tabular}

\section{Disscusion of Results}

The findings of this study can be summarized below. First, all of the relationships suggested in the original Unified Theory of Adoption and Use of Technology (UTAUT) were supported except for the impact of social influence on continuous usage intention. Second, continuous usage intention and actual usage were shown to be significant. Finally, our main inquiry, the moderation effect of privacy concerns, was also tested through the group comparison method suggested by [5]

It important to note that our research findings revealed that when an individual has the intention to use LBS due to social influences, the risky shift phenomenon occurs due to significant others. Meanwhile, when LBS usage intention stems from performance expectancy, cautious shifts occur instead of risky shifts. In other words, in contrast to the findings of previous research, our findings show that privacy concerns may not always be the main causes of slow LBS diffusion. Rather, the effects of privacy concerns on LBS show different patterns depending on what originally motivated the individuals to use their LBS applications. Our findings also indicate that it is necessary to investigate the effects of privacy concerns on a better contingent basis, examining how effects vary according to the types of LBS as well as their objectives and popularity.

\section{Conclusion}

This research was able to highlight the major significance of LBS applications and how it helped technology companies like Google and Facebook to drive huge revenue growth and also provided superior value to Uber transport service across the world. More so, withthe proliferation of smartphones and mobile Internet service, LBS applications may finally become 'killer apps.' However, the 'whenever and wherever' and 'always-on' nature of LBS can pose a threat to users' location privacy. In this context, this study attempted to understand the post-adoptive behaviors of LBS application users by concentrating on the moderating effects of users' privacy concerns. The study revealed that cautious shifts are still a factor in the relationship between performance expectancy and continuous usage intention of LBS, a finding that is consistent with traditional views. Meanwhile, risky shifts occur due to the effect of social influences in the presence of stronger privacy concerns. The results of this study have practical implications for interested parties, including LBS application developers and service providers.

Finally, werecommend that small and medium scale business in Nigeria should focus on how to up their games by adoption of LBS application in connecting customers so as to stay competitive in the ever dynamicglobal market.

\section{References}

[1] Berg Insight, "Mobile Location-Based Services," [Available: Year 2012] http://www.berginsight.com/reportpdf/productsheet/bi-lbs8ps.pdf[Accessed: $\quad$ September $\quad 19, \quad 2017]$ http://digitalcommons.kennesaw.edu/cgi/viewcontent.cgi?artic $\mathrm{le}=1068 \&$ context $=$ ajis. 
[2] Isaac M. Mbiti and Jenny C. Aker, 2010. "Mobile Phones and Economic Development in Africa". [online] Journal Economic Perspectives Vol. 24, No 3, pp.207-32 [Available: https://www.aeaweb.org/articles?id=10.1257/jep.24.3.207] [Accessed: $24^{\text {th }}$ March, 2018]

[3] HeajungYun et al. 2011, "What determines the actual use of mobile web browsing services? A contextual study in korea", Google Scholar. [Available: https://scholar.google.com] [Accessed: 24 ${ }^{\text {th }}$ March, 2018].

[4] Heng Xu \& S Gupta 2009, "The effect of privacy concerns and personal innovativeness on potential and experienced customers' adoption of location based services". Electronic Market 19 (2-3), 137-149. 2009.

[5] Martins S. Chin, Yuan K. Chou [2004], "Modelling Social Infrastructure and Economic Growth", Australia Economic Papers, Volume 43, Issue 2, Wiley online library.[ Available: http://libguides.murdoch.edu.au/IEEE/ejournal] [Accessed: $24^{\text {th }}$ March 2018].

[6] HaejungYun, Dongho Han, Choong C. Lee. "Understanding the use of location-based service applications: Do privacy concerns matters?", Journal of Electronic Commerce Research, Vol 14, No 3, 2013.

[7] Xu, H. and S. Gupta, "The Effects of Privacy Concerns and Personal Innovativeness on Potential and Experienced Customers' Adoption of Location-Based Services," Electronic Markets, Vol. 19, No. 2: 137-149, 2009.

[8] Yu, C. S., "Factors Affecting Individuals to Adopt Mobile Banking: Empirical Evidence from the UTAUT Model," Journal of Electronic Commerce Research, Vol. 1, No. 2: 104121, 2012.

[9] Zhou, T., "Examining Location-Based Services Usage from the Perspectives of United Theory of Acceptance and Use of Technology and Privacy Risk," Journal of Electronic Commerce Research, Vol. 13, No. 2: 135-144, 2012.

[10] Park, S., M. Keil, J. Kim, and G. W. Bock, “Understanding Overbidding Behavior in C2C Auctions: An Escalation Theory Perspective," European Journal of Information Systems, Vol. 21, No. 6: 643-663, 2012.

[11] Manav Singhal1, Anupam Shukla. "Implementation of Location based Services in Android using GPS and Web Services"IJCSI International Journal of Computer Science Issues, Vol. 9, Issue 1, No 2, January 2012. ISSN (Online): 1694-0814. [Available: $27^{\text {th }}$ September, 2017].
[12] FolasadeDahunsi, “ Towards the Deployment and Adoption of Location Based Services for optimum mobile communication operations in Africa"[Online], University of Witwatersrand, South Africa, Africa Journal of Information System Volume 4, Issue 2. [Available: https://pdfs.semanticscholar.org]. [Accessed: $10^{\text {th }}$ October, 2017].

[13] Beinat, E., and Dias, E. S. (2003). Location services and accuracy. An analysis for field work applications. Retrieved from

[14] Work paper GIPSY project, (Institution for Environmental Studies (IVM)) Amsterdam, the Netherlands: http://www.feweb.vu.nl/gis/research/LUCAS/

Publications/docs/gipsy_2004_7.pdf. [14] African Development Bank. (2011). Gender, Poverty and Environmental Indicators on African Countries. Economic andSocial Statistics Division Statistics Department African Development Bank Temporary Relocation Agency (TRA). Volume 12

[15] BuddeComm and Chiltern Magazine Services Ltd. (2011). Insights to the African Telecom Market 2011: Analysis, forecasts and commentary. England, UK: Chiltern Magazine Services Ltd.

[16] Dahunsi, F. M., and Dwolatzky, B. (2011). An Empirical investigation of the accuracy of Location Based Services in South Africa. Journal of Location Based Service, DOI: 10.1080/17489725.2011.625303.

[17] International Fund for Agricultural Development (IFAD). (2010). Rural poverty in Africa. Retrieved from http://www.ruralpovertyportal.org/web/guest/region/home/tags /africa.

[18] Ryu, H. S., "Possibilities and Opportunities of Location-Based Advertising and Commerce," in Internet \& Security Issue, Korea Internet \& Security Agency: 5-22, 2011.

[19] Rao, B. and L. Minakakis, "Evolution of Mobile LocationBased Services," Communications of the ACM, Vol. 46, No. 12: 61-65, 2003.

[20] Sheng, H., F. Nah, and K. Siau, “An Experimental Study on Ubiquitous Commerce Adoption: Impact of Personalization and Privacy Concerns," Journal of the Association for Information Systems, Vol. 9, No. 6: 344-377, 2008. 